OPEN ACCESS

Edited by:

Renzo Mazzarotto,

Integrated University Hospital

Verona, Italy

Reviewed by:

Alessandra lurlo,

IRCCS Ca 'Granda Foundation

Maggiore Policlinico Hospital, Italy

Nicola Simoni,

Integrated University Hospital

Verona, Italy

*Correspondence:

Khinh Ranh Voong

kvoong1@jhmi.edu

Specialty section:

This article was submitted to

Radiation Oncology,

a section of the journal

Frontiers in Oncology

Received: 23 December 2021

Accepted: 26 January 2022

Published: 24 February 2022

Citation:

Sloan L, Naik RP, Umrau K, Xian RR, Marrone $K A$ and Voong $K R$ (2022) Case Report: Hematologic Recovery Following Stereotactic Ablative

Radiotherapy in a Patient With EarlyStage Non-Small Cell Lung Cancer and Paraneoplastic Myelofibrosis.

Front. Oncol. 12:842620. doi: 10.3389/fonc.2022.842620

\section{Case Report: Hematologic Recovery Following Stereotactic Ablative Radiotherapy in a Patient With Early- Stage Non-Small Cell Lung Cancer and Paraneoplastic Myelofibrosis}

\author{
Lindsey Sloan ${ }^{1,2}$, Rakhi P. Naik ${ }^{3}$, Kavita Umrau ${ }^{4}$, Rena Ruiyu Xian ${ }^{4}$, Kristen A. Marrone ${ }^{5}$ \\ and Khinh Ranh Voong ${ }^{2 *}$ \\ ${ }^{1}$ Department of Radiation Oncology, University of Minnesota Medical School, Minneapolis, MN, United States, ${ }^{2}$ Department \\ of Radiation Oncology and Molecular Radiation Sciences, Johns Hopkins School of Medicine, Baltimore, MD, United States, \\ ${ }^{3}$ Department of Hematology, Johns Hopkins School of Medicine, Baltimore, MD, United States, ${ }^{4}$ Department of Pathology, \\ Johns Hopkins School of Medicine, Baltimore, MD, United States, ${ }^{5}$ Department of Oncology, Johns Hopkins School of \\ Medicine, Baltimore, MD, United States
}

Herein, we report the first case presentation of paraneoplastic myelofibrosis associated with cancer. Paraneoplastic syndromes occur in some patients with thoracic malignancies; however, myelofibrosis is not commonly seen in non-small cell lung cancer (NSCLC). We report a case of myelofibrosis in a patient with a new diagnosis of NSCLC that resolved after stereotactic ablative radiotherapy (SABR). In conclusion, NSCLC may evoke unexpected systemic effects that resolve with treatment.

Keywords: NSCLC, SAbR, paraneoplastic, case, report

\section{INTRODUCTION}

Paraneoplastic syndromes are extreme examples of the systemic influence of cancer. They are defined as a constellation of spatially distant signs and/or symptoms of a primary cancer (1). Paraneoplastic syndromes are believed to occur infrequently; however, their prevalence may be underestimated due to underreporting. Small cohort studies have reported the incidence of paraneoplastic syndromes to be $11 \%-16 \%$ in lung cancer patients (2-4). Paraneoplastic disorders are diagnoses of exclusion; however, diagnostic criteria have been developed for some syndromes with available specialized testing $(5,6)$. These syndromes occur due to two main mechanisms: the generation of physiologic antibodies directed against a tumor epitope that cross reacts with normal tissue (neurologic paraneoplastic syndromes) and abhorrent production of a functional soluble factor ectopically produced by tumor cells (endocrine paraneoplastic syndromes) (7). Antibodies against neuronal/glial tissue are most commonly appreciated within neurologic paraneoplastic syndromes, as in paraneoplastic cerebellar degeneration (anti-Yo or anti-Hu antibodies) (8) and Lambert-Eaton myasthenia syndrome (anti-P/Q type voltage-gated calcium channel antibodies) (9). Syndromes characterized by endocrine or metabolic disturbances may involve production of inappropriate or supra-physiologic levels of a protein (hypercalcemia via parathyroid or parathyroid hormone-related peptide) (10). Specific treatment algorithms for some 
paraneoplastic syndromes do exist, especially in antibodymediated syndromes and those requiring urgent medical intervention (10). Management, however, of the underlying cancer is often considered the first step in treatment (6).

Out of all thoracic malignancies, paraneoplastic syndromes such as Cushing's syndrome and syndrome of inappropriate antidiuretic hormone secretion are most commonly associated with small cell lung cancer (6). In non-small cell lung cancer (NSCLC), end organ damage to nervous and hormoneresponsive tissue by paraneoplastic syndromes is most often reported, but involvement of the hematopoietic system also occurs infrequently $(2,3)$. A recent Danish registry cohort study estimated the incidence of hematologic paraneoplastic syndromes in NSCLC to be $1.9 \%$ (2). Paraneoplastic syndromes causing anemia are rare. In terms of thoracic cancer-related anemia, pure red cell aplasia in patients with thymoma is one of the more commonly discussed blood-related paraneoplastic syndromes (11). Here, we report the first known case of paraneoplastic myelofibrosis in lung cancer.

\section{CASE DESCRIPTION}

A 69-year-old non-smoking patient was seen in our thoracic multidisciplinary clinic to discuss management options for his newly diagnosed Stage 1A3, T1cN0M0 lung adenocarcinoma (programmed death ligand 1 score $<1 \%$ ). During this visit, he was noticeably unwell and reported new-onset dyspnea.

Upon admission, he was found to have a profound normocytic anemia on complete blood count (hemoglobin: $4.2 \mathrm{~g} / \mathrm{dl}$, low; reticulocyte percent: $0.3 \%$, low; platelets/white blood cells: within normal limits) Peripheral blood smear (Figure 1) depicted red blood cells with a normal structure with a notable absence of teardrop forms. Further emergent workup identified a lactate dehydrogenase (LDH) of $214 \mathrm{U} / \mathrm{l}$ (high), haptoglobin of $205 \mathrm{mg} /$ $\mathrm{dl}$ (high), iron of $186 \mu \mathrm{g} / \mathrm{dl}$ (high), transferrin $150 \mathrm{mg} / \mathrm{dl}$ (low), total iron binding capacity of $188 \mu \mathrm{g} / \mathrm{dl}$ (low), and percent saturation of 99\% (high). Additional laboratory tests were not suggestive of hemolysis despite mildly elevated $\mathrm{LDH}$ and haptoglobin: total bilirubin $0.7 \mathrm{mg} / \mathrm{dl}$ and alanine aminotransferase (ALT) $28 \mathrm{U} / \mathrm{l}$. His anemia required transfusion of 5 units of blood. Trauma and gastrointestinal sources of blood loss were ruled out.

Hematology was consulted. The patient was not found to have splenomegaly on exam. Additional laboratory workup of the patient's anemia revealed a ferritin of $1395 \mathrm{ng} / \mathrm{dl}$ (high), reticulocyte count of $7.2 \mathrm{~K} / \mathrm{cu} \mathrm{mm} \mathrm{3 \%}$ (low), serum folate of 6.6 $\mathrm{ng} / \mathrm{ml}$ (normal), vitamin B12 of $427 \mathrm{pg} / \mathrm{ml}$ (normal), and serum erythropoietin of $709.3 \mathrm{mIU} / \mathrm{ml}$ (high). Molecular diagnostic and antibody testing for viral infections were negative. ANA was positive (1:360). Fluorescence in situ hybridization (FISH) for adult acute myeloid leukemia (AML) and myelodysplastic syndromes (MDS) identified no mutations using probes $5 \mathrm{p} 15.2$ (D5S23, D5S721), 5q31 (EGR1), 7cen(D7Z1), 7q31 (D7S522), 8cen (D8Z2), 11q23 (MLL), 20q12 (D20S108), and 20q13.12 (D20S150). The patient's karyotype was normal 46,XY (12). Next-generation sequencing (NGS), comprising a panel of 87 genes, was performed and was negative for common driver

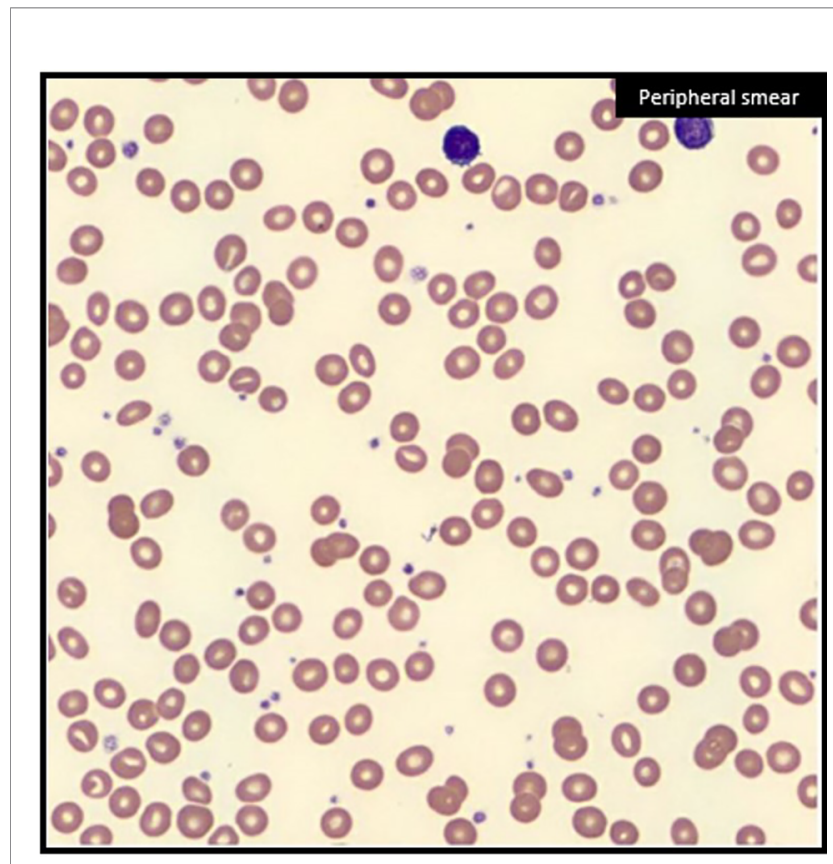

FIGURE 1 | Normocytic anemia on blood smear. Peripheral blood smear at the time initial diagnosis with findings of normocytic anemia with reticulocytopenia, but notable absence of teardrop forms (dacrocytes).

mutations of hematologic cancers including JAK2 and MPL. Bone marrow aspirate was performed (Figure 2). Flow cytometry identified a $1.5 \%$ B cell clone of unknown significance with a chronic lymphocytic leukemia (CLL) phenotype. Ultimately, the patient was diagnosed with myelofibrosis of paraneoplastic or autoimmune etiology. He continued to have refractory and symptomatic anemia with persistent reticulocytopenia despite treatment with 2 weeks of oral steroids.

The care plan was to proceed with curative management of the patient's non-small cell lung cancer (NSCLC) with stereotactic ablative radiotherapy (SABR), after which treatment of his transfusion-dependent anemia with rituximab would be considered. The patient received SABR (48 Gy in 4 fractions) for his Stage 1A3 NSCLC without adverse or unexpected events. Within 1 week of radiotherapy (RT), the patient's reticulocyte count increased to $5.1 \%$ (above normal limits) and hemoglobin increased from 7.9 to $8.1 \mathrm{~g} / \mathrm{dl}$. He did not experience any side effects from SABR. He had normalization of his hemoglobin for an extended 14 months after SABR $(16 \mathrm{~g} / \mathrm{dl})$ without need for interval hematologic intervention. The patient developed relapse of his autoimmune fibrosis in the setting of vaccination against the coronavirus disease 2019 (COVID-19) and redeveloped a transfusion-dependent anemia. Positronemission tomography at the time of redevelopment of his transfusion-dependent anemia showed no evidence of lung cancer recurrence. Repeat bone-marrow biopsy showed hypercellular bone marrow with mildly increased reticulin fibrosis. The persistence of a small CLL clone was detected and for which he received rituximab without response. This patient remains transfusion dependent. The patient provided informed 


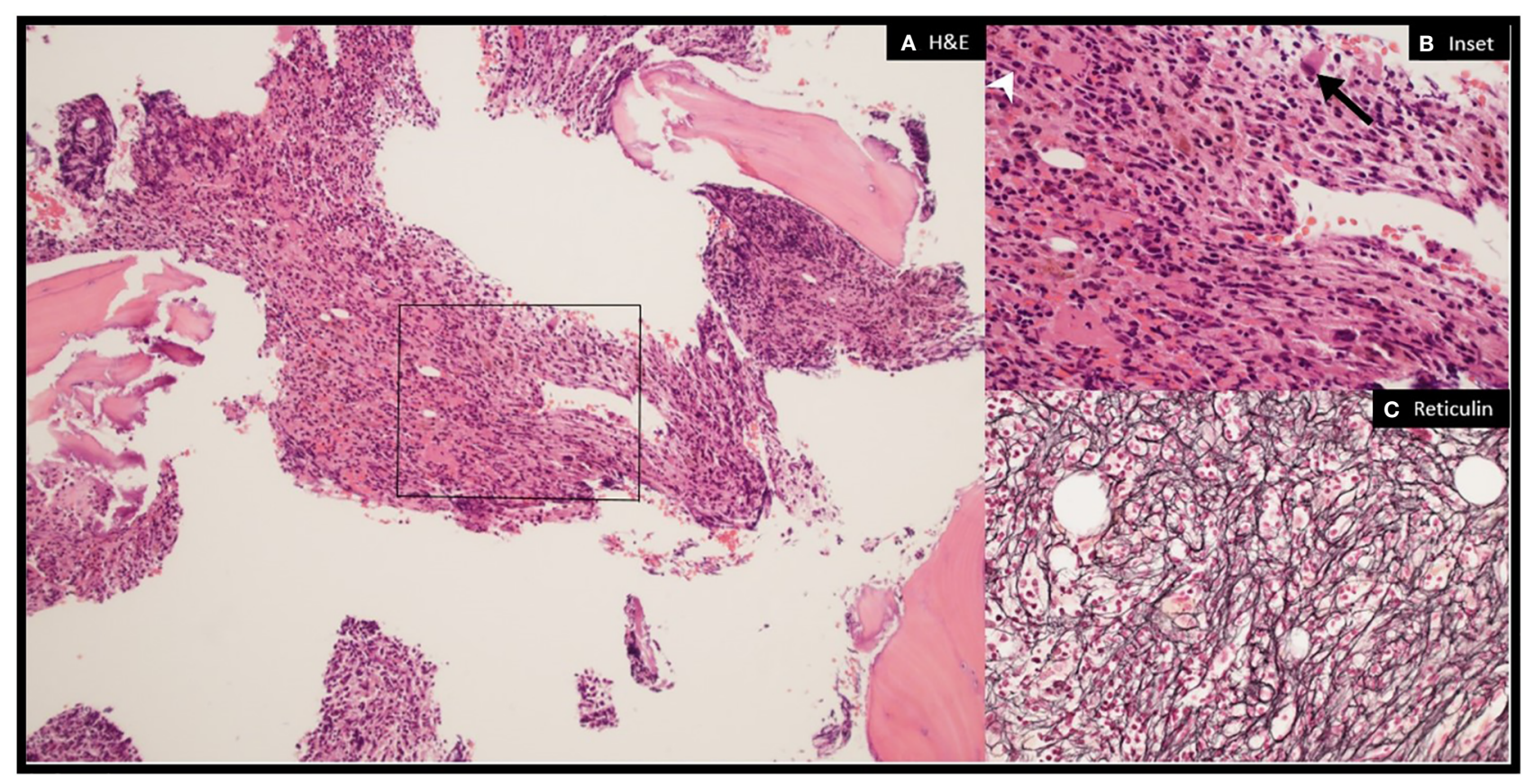

FIGURE 2 | Myelofibrosis on bone marrow biopsy. Bone marrow biopsy showing markedly hypercellular and fibrotic marrow with trilineage hematopoiesis. The megakaryocytes are adequate in number but show atypical forms including, large hypo-lobated cells (black arrow), cells with hyperchromatic nuclei, as well as small mono-lobated forms (white arrowhead) (A) (×10) and (B) (×40): H\&E). Reticulin stain demonstrates moderate-to-severe reticulin fibrosis, MF-2 to MF-3 based on WHO grading (C) $(\times 40)$ : reticulin).

consent for this case report, and the timeline of his hematopoietic response after completion of SABR is depicted in Figure 3.

\section{DISCUSSION}

The patient initially presented with severe, likely acute, anemia at his consultation for radiation therapy for an early-stage NSCLC. His hemoglobin was found to be $4 \mathrm{~g} / \mathrm{dl}$, requiring urgent transfusion. Further workup of his anemia ruled out hemolysis, as he had a mildly elevated LDH and haptoglobin in the presence of a normal total bilirubin and ALT with no teardrop-shaped red blood cells on peripheral blood smear. Although teardrop forms are typically identified on bone marrow fibrosis, we suspect the lack of dacrocytes seen here likely relates to the acute nature of the patient's clinical presentation. This would be analogous to acute panmyelosis with myelofibrosis, a rapidly progressive disease, which shows severe marrow fibrosis without circulating teardrop cells. Since the lifespan of a red blood cell is 120 days and this patient's symptoms occurred much more quickly, we suspect that our assessment of the blood smear was prior to the development of dacrocytes. Severe anemia, as seen with our patient's hemoglobin of $4 \mathrm{~g} / \mathrm{dl}$, from chronic myelofibrosis is usually accompanied by other blood abnormalities and splenomegaly. Splenomegaly was not seen. However, cases of acute myelofibrosis and autoimmune myelofibrosis are often not accompanied by splenomegaly, and autoimmune myelofibrosis, in particular, may not be associated with pancytopenia. In this case, the red cell line was primarily affected.

Although paraneoplastic myelofibrosis has never been reported to our knowledge, abnormal hematologic findings in cancer patients are common. These alterations may be explained by the use of cancer-directed systemic therapies, infection, a chronic disease state, the presence of bone marrow metastases, or steroid use (13). When paraneoplastic syndromes are responsible for hematologic finding associated with cancer, they are usually increases in a circulating cell type (e.g., leukocytes, erythrocytes, thrombocytes) and less commonly a reduction in a cell population (14). Castello and colleagues were able to study cancer patients with under-functioning bone marrow in detail (15). Out of a group of mixed histology solid cancer patients without known metastatic bone marrow involvement, they found that a decrease in multiple hematopoietic cell lineages including erythrocytes, granulocytes, and megakaryocytes occurred most commonly in patients with gastrointestinal cancers, followed by those with lung cancers (15).

Table 1 summarizes the available literature regarding hematologic paraneoplastic syndromes associated with NSCLC. Hypereosinophilia and leukemoid reactions, or massive increases in white blood cells with a predominance of neutrophils, are the most commonly reported hematopoietic paraneoplastic syndromes in NSCLC. Hypereosinophilia is defined as more than 1,500 eosinophils per $\mu \mathrm{L}$ of blood (17); leukemoid reactions are characterized by more than 50,000 white blood cells per $\mu \mathrm{L}$ of blood (22). A link between a growth factor that supports the 


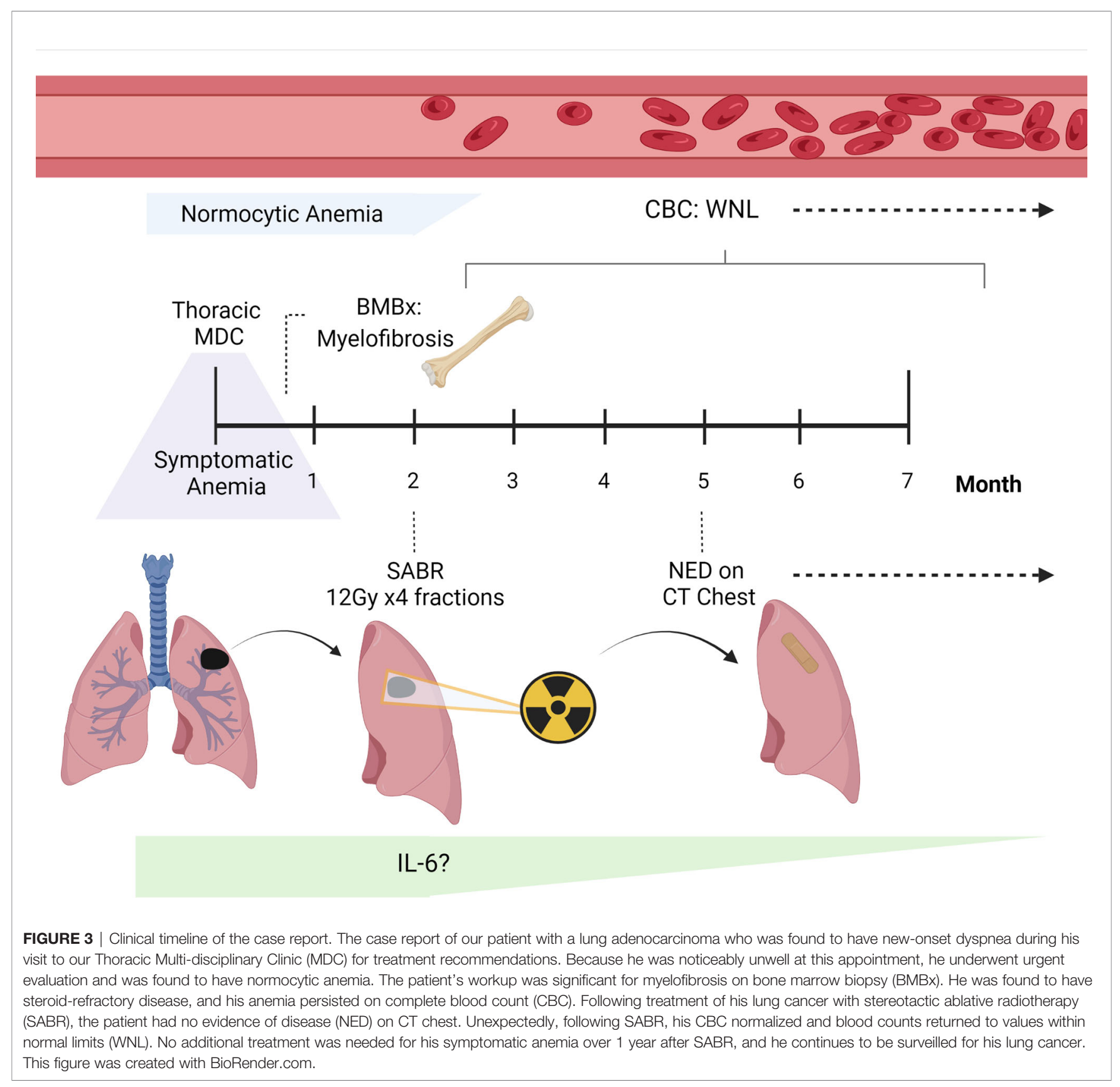

maturation of eosinophil progenitor cells, interleukin (IL)-5, and hypereosinophilia is known $(24,27)$. In support of the chief role for tumor cells in some paraneoplastic syndromes, one case report found high levels of systemic IL-5 to fall following the resection of a NSCLC (27). Similar to the connection of IL-5 and hypereosinophilia, overproduction of granulocyte-colony stimulating factor (G-CSF) has been attributed as the cause of paraneoplastic leukemoid relations in some patients (13). One case report found a robust expression of G-CSF to explain the increase in circulating leukocytes in conjunction with the marrow-active cytokine, interleukin (IL)-6 (22). Unfortunately, both hypereosinophilia and leukemoid reactions are associated with poor outcomes in cancer patients $(13,26)$. This suggests that further understanding of paraneoplastic mechanisms, which may occur subclinically in more patients than are formally diagnosed with paraneoplastic syndromes, could be important to the development of future novel anti-cancer therapies and treatment adjuvants.

Of note, reports of cell changes due to autoimmune antibody production were not included in Table 1. We acknowledge that paraneoplastic syndromes may also be associated with expansion of specific peripheral lymphocyte populations. Antibodymediated myelofibrosis remains in the differential diagnosis for our patient, especially in the setting of (1) his normal lymphocyte 
TABLE 1 | Hematologic paraneoplastic syndromes reported in non-small cell lung cancer patients.

\begin{tabular}{|c|c|c|c|c|}
\hline Year & First author & $\begin{array}{l}\text { Study } \\
\text { type }\end{array}$ & Lung cancer histology & $\begin{array}{l}\text { Hematologic paraneoplastic } \\
\text { finding }\end{array}$ \\
\hline 2021 & Wehbe (16) & $\begin{array}{l}\text { Case } \\
\text { report }\end{array}$ & Adenocarcinoma & Hypereosinophilia \\
\hline 2020 & Akkad (17) & $\begin{array}{l}\text { Case } \\
\text { report }\end{array}$ & Adenocarcinoma & $\begin{array}{l}\text { Hypereosinophilia; leukemoid } \\
\text { reaction }\end{array}$ \\
\hline 2020 & Chahine (18) & $\begin{array}{l}\text { Case } \\
\text { report }\end{array}$ & Adenocarcinoma & Leukemoid reaction \\
\hline 2019 & Mouhayyar (19) & $\begin{array}{l}\text { Case } \\
\text { report }\end{array}$ & Adenocarcinoma & Hypereosinophilia \\
\hline 2018 & $\begin{array}{l}\text { Abughanimeh } \\
(20)\end{array}$ & $\begin{array}{l}\text { Case } \\
\text { report }\end{array}$ & Adenocarcinoma & Hypereosinophilia \\
\hline 2016 & Yu (21) & $\begin{array}{l}\text { Case } \\
\text { report }\end{array}$ & Adenocarcinoma & Anemia; thrombocytopenia \\
\hline 2015 & McCoach (22) & $\begin{array}{l}\text { Case } \\
\text { report }\end{array}$ & Adenocarcinoma & Leukemoid reaction \\
\hline 2014 & Youssef (23) & $\begin{array}{l}\text { Case } \\
\text { report }\end{array}$ & Squamous cell carcinoma & Hypereosinophilia \\
\hline 2013 & Lo (24) & $\begin{array}{l}\text { Case } \\
\text { report }\end{array}$ & Adenocarcinoma & Hypereosinophilia \\
\hline 2012 & Riesenberg (25) & $\begin{array}{l}\text { Case } \\
\text { report }\end{array}$ & Adenocarcinoma & Leukemoid reaction \\
\hline 2011 & Verstraeten (26) & $\begin{array}{l}\text { Case } \\
\text { report }\end{array}$ & Non-small cell lung cancer ${ }^{a}$ & Hypereosinophilia \\
\hline 2007 & Pandit (27) & $\begin{array}{l}\text { Case } \\
\text { report }\end{array}$ & Large cell carcinoma & Hypereosinophilia \\
\hline 2001 & Kasuga (13) & $\begin{array}{l}\text { Case } \\
\text { series }\end{array}$ & $\begin{array}{c}32 \text { Non-small cell lung cancer (14 adenocarcinoma; } 12 \text { squamous cell carcinoma; } 6 \text { large } \\
\text { cell carcinoma) }\end{array}$ & Leukocytosis \\
\hline 1992 & $\begin{array}{l}\text { Sans-Sabrafen } \\
(28)\end{array}$ & $\begin{array}{l}\text { Case } \\
\text { series }\end{array}$ & 2 adenocarcinomas & $\begin{array}{l}\text { Refractory anemia with ring } \\
\text { sideroblasts }\end{array}$ \\
\hline 1984 & $\operatorname{Raz}(14)$ & $\begin{array}{l}\text { Case } \\
\text { series }\end{array}$ & 3 non-small cell lung cancer ( 2 adenocarcinoma, 2 squamous cell carcinoma) & Myelodysplasia \\
\hline
\end{tabular}

${ }^{a}$ This report was of a patient with non-small cell lung cancer, without additional histologic subclassification. General lab abnormality definitions: Leukemoid reaction >50,000 cells/ $\mu$;; leukocytosis >10,000 cells/ $\mu$; hypereosinophilia $>1,500 \mathrm{cells} / \mu$ l.

counts on his initial CBC test and (2) his persistent anemia despite trial of rituximab for the small population of CLL cells found on his repeat bone marrow biopsy over 1 year later. Further, because we did not perform immunoassays to detect bone marrow-reactive antibodies, autoimmune etiologies of our patient's anemia cannot be excluded despite steroids not being effective in correcting his anemia.

Although initially it appeared that our patient had two independent disease processes, myelofibrosis and NSCLC, the complete resolution of the patient's anemia after SABR suggested a connected pathophysiology. Primary myelofibrosis has been associated with excess circulating serum cytokines including, IL-6 (11), which is also highly expressed by NSCLC tumor cells (12). IL-6 has been reported to be involved in the pathophysiology of multiple paraneoplastic syndromes, including the aforementioned leukemoid reactions (29-31). As cytokines have been reported to be responsible for some paraneoplastic hematopoietic syndromes in patients with NSCLC, as described above (32), we propose that one potential mechanism to explain these findings could involve systemic IL-6 levels. We hypothesize that tumor cells secreting IL-6 may have been responsible for the development of myelofibrosis in this patient (Figure 3). Further, these tumor cells were destroyed by ablative radiation which subsequently resulted in normal bone marrow function and red blood cell production. We are limited in the retrospective nature of this report as we cannot evaluate for the level of IL-6 prior to and after receipt of SABR; however, clearly SABR was the only therapeutic intervention that occurred prior to this patient's hematopoietic recovery. As conventionally fractionated radiation has been shown to have an effect on serum IL-6 (33), this mechanism is likely to be much more complex. A translational study of the biological effects of even relatively small volumes of ablated tissue, as seen in SABR for early lung cancers, is needed. Finally, further hematologic cytokine level evaluation will be needed if there is future clinical concern of tumor progression.

The recurrence of the patient's anemia following his first COVID-19 vaccination is an interesting observation. Temporally, the relapse of the patient's condition did appear to be related to the COVID-19 vaccine. We would assume that this is immune-mediated, although we cannot speculate on the exact mechanism. Certainly, his underlying B cell clone with CLL immunophenotype likely predisposed to immune complications. Other autoimmune phenomena such as immune thrombocytopenia purpura (ITP) certainly are known to occur with COVID infection and with COVID vaccination.

In conclusion, this report is the first to identify resolution of a myelofibrosis associated with cancer. The anemia found in our patient was due to a myelofibrotic process of the bone marrow caused by the patient's small, but biologically active, lung cancer. 
The patient we describe experienced hematologic recovery after treatment his NSCLC with SABR. One possible cytokine responsible may be IL-6.

\section{METHODS}

\section{Literature Search}

PubMed was queried for available full-text articles printed in the English language using the terms "paraneoplastic non-small cell lung cancer" and "paraneoplastic syndrome lung adenocarcinoma". Published cases reporting abnormalities in the quantity of common cellular blood components due to a paraneoplastic syndrome from NSCLC were reviewed and are shown in Table 1.

\section{Patient Perspective}

The patient provided written consent for the use of his clinical case for the education purposes of this article. The patient continues to undergo treatment for CLL and management of his recurrent anemia.

\section{DATA AVAILABILITY STATEMENT}

The raw data supporting the conclusions of this article will be made available by the authors, without undue reservation.

\section{REFERENCES}

1. Thapa B, Ramphul K. Paraneoplastic Syndromes. Treasure Island (FL: StatPearls (2021).

2. Miret M, Horvath-Puho E, Deruaz-Luyet A, Sorensen HT, Ehrenstein V. Potential Paraneoplastic Syndromes and Selected Autoimmune Conditions in Patients With Non-Small Cell Lung Cancer and Small Cell Lung Cancer: A Population-Based Cohort Study. PloS One (2017) 12(8):e0181564. doi: 10.1371/journal.pone.0181564

3. Kanaji N, Watanabe N, Kita N, Bandoh S, Tadokoro A, Ishii T, et al. Paraneoplastic Syndromes Associated With Lung Cancer. World J Clin Oncol (2014) 5(3):197-223. doi: 10.5306/wjco.v5.i3.197

4. Dumansky YV, Syniachenko OV, Stepko PA, Yehudina YD, Yu SO. Paraneoplastic Syndrome in Lung Cancer. Exp Oncol (2018) 40(3):239-42. doi: 10.31768/2312-8852.2018.40(3):239-242

5. Zoccarato M, Grisold W, Grisold A, Poretto V, Boso F, Giometto B. Paraneoplastic Neuropathies: What's New Since the 2004 Recommended Diagnostic Criteria. Front Neurol (2021) 12:706169. doi: 10.3389/ fneur.2021.706169

6. Upadhya P, Ananthraju A, Vadala R, Mohapatra MM. Endocrine Paraneoplastic Syndromes in Lung Cancer: A Respiratory Physician's Perspective. Adv Respir Med (2021) 89(4):403-12. doi: 10.5603/ ARM.a2021.0075

7. Shamji FM, Beauchamp G, Maziak DE, Cooper J. Paraneoplastic Syndromes in Lung Cancers: Manifestations of Ectopic Endocrinological Syndromes and Neurologic Syndromes. Thorac Surg Clin (2021) 31(4):519-37. doi: 10.1016/ j.thorsurg.2021.06.001

8. Garza M, Piquet AL. Update in Autoimmune Movement Disorders: Newly Described Antigen Targets in Autoimmune and Paraneoplastic Cerebellar Ataxia. Front Neurol (2021) 12:683048. doi: 10.3389/fneur.2021.683048

9. Pellkofer HL, Armbruster L, Krumbholz M, Titulaer MJ, Verschuuren JJ, Schumm F, et al. Lambert-Eaton Myasthenic Syndrome Differential Reactivity of Tumor Versus non-Tumor Patients to Subunits of the

\section{ETHICS STATEMENT}

Ethical review and approval were not required for the study on human participants in accordance with the local legislation and institutional requirements. The patients/participants provided their written informed consent to participate in this study. Written informed consent was obtained from the individual(s) for the publication of any potentially identifiable images or data included in this article.

\section{AUTHOR CONTRIBUTIONS}

All authors were involved in the care of the patient, as well as the writing and review of the manuscript. LS was directly involved in literature review. RPN provided hematology expertise and the case images. KAM was involved in oncologic care of this patient. $\mathrm{KU}$ and RRX were involved in pathologic diagnosis of the patient and figure preparation. KRV oversaw radiation oncology care. All authors contributed to the article and approved the submitted version.

\section{FUNDING}

Open access fees were paid by KRV from gift funds.
Voltage-Gated Calcium Channel. J Neuroimmunol (2008) 204(1-2):136-9. doi: 10.1016/j.jneuroim.2008.08.002

10. Spinazze S, Schrijvers D. Metabolic Emergencies. Crit Rev Oncol Hematol (2006) 58(1):79-89. doi: 10.1016/j.critrevonc.2005.04.004

11. Lesire B, Durieux V, Grigoriu B, Girard N, Berghmans T. Management of Thymoma Associated Autoimmune Pure Red Cell Aplasia: Case Report and Systematic Review of the Literature. Lung Cancer (2021) 157:131-46. doi: 10.1016/j.lungcan.2021.05.010

12. Asselin-Paturel C, Echchakir H, Carayol G, Gay F, Opolon P, Grunenwald D, et al. Quantitative Analysis of Th1, Th2 and TGF-Betal Cytokine Expression in Tumor, TIL and PBL of Non-Small Cell Lung Cancer Patients. Int J Cancer (1998) 77(1):7-12. doi: 10.1002/(SICI)1097-0215(19980703)77:1<7::AIDIJC2>3.0.CO;2-Y

13. Kasuga I, Makino S, Kiyokawa H, Katoh H, Ebihara Y, Ohyashiki K. TumorRelated Leukocytosis Is Linked With Poor Prognosis in Patients With Lung Carcinoma. Cancer (2001) 92(9):2399-405. doi: 10.1002/1097-0142 (20011101)92:9<2399::AID-CNCR1588>3.0.CO;2-W

14. Raz I, Shinar E, Polliack A. Pancytopenia With Hypercellular Bone Marrow-a Possible Paraneoplastic Syndrome in Carcinoma of the Lung: A Report of Three Cases. Am J Hematol (1984) 16(4):403-8. doi: 10.1002/ajh.2830160411

15. Castello A, Coci A, Magrini U. Paraneoplastic Marrow Alterations in Patients With Cancer. Haematologica (1992) 77(5):392-7.

16. Wehbe H, Kozah M, Koubaissi SA. Lung Adenocarcinoma With Paraneoplastic Hyper-Eosinophilia Not Responding To Pembrolizumab. Clin Med Insights Circ Respir Pulm Med (2021) 15:11795484211030164. doi: 10.1177/11795484211030164

17. Akkad N, Jiang Y, Shin D. Leucocytosis and Stroke in a Lung Cancer Patient. Eur J Case Rep Intern Med (2020) 7(11):001872. doi: 10.12890/2020_001872

18. Chahine Z, Samhouri Y, Jayakrishnan T, Monga D. Leukemoid Reaction Causing Arterial Thrombus in a Patient With Lung Adenocarcinoma. BMJ Case Rep (2020) 13(10):1-3. doi: 10.1136/bcr-2020-235389

19. El Mouhayyar C, Chehab O, Khalil E, Najeeb Al Hallak M, Kanj A, Bishop C. Paraneoplastic Leukemoid Reaction in a Patient With Metastatic 
Adenocarcinoma of the Lung. Clin Case Rep (2020) 8(1):9-12. doi: 10.1002/ ccr3.2536

20. Abughanimeh O, Tahboub M, Abu Ghanimeh M. Metastatic Lung Adenocarcinoma Presenting With Hypereosinophilia. Cureus (2018) 10(6): e2866. doi: 10.7759/cureus.2866

21. Yu H, Fu R, Wang H, Liu H, Shao Z. Paraneoplastic Evans Syndrome in a Patient With Adenocarcinoma of the Lung: A Case Report. Thorac Cancer (2017) 8(1):57-60. doi: 10.1111/1759-7714.12398

22. McCoach CE, Rogers JG, Dwyre DM, Jonas BA. Paraneoplastic Leukemoid Reaction as a Marker of Tumor Progression in Non-Small Cell Lung Cancer. Cancer Treat Commun (2015) 4:15-8. doi: 10.1016/j.ctrc.2015.03.003

23. Youssef M, Kechida M, Cheikhmohamed S, Moussa A, Zili J. Multiple Paraneoplastic Syndromes Revealing Non-Small Cell Lung Carcinoma. Pan Afr Med J (2014) 19:237. doi: 10.11604/pamj.2014.19.237.4409

24. Lo CH, Jen Y-M, Tsai W-C, Chung P-Y, Kao W-Y. Rapidly Evolving Asymptomatic Eosinophilia in a Patient With Lung Adenocarcinoma Causes Cognitive Disturbance and Respiratory Insufficiency: Case Report. Oncol Lett (2013) 5(2):495-8. doi: 10.3892/ol.2012.1020

25. Riesenberg H, Muller F, Gorner M. Leukemoid Reaction in a Patient With Adenocarcinoma of the Lung: A Case Report. J Med Case Rep (2012) 6:211. doi: $10.1186 / 1752-1947-6-211$

26. Verstraeten AS, De Weerdt A, van Den Eynden G, Van Marck E, Snoeckx A, Jorens PG. Excessive Eosinophilia as Paraneoplastic Syndrome in a Patient With Non-Small-Cell Lung Carcinoma: A Case Report and Review of the Literature. Acta Clin Belg (2011) 66(4):293-7. doi: 10.2143/ACB.66.4.2062571

27. Pandit R, Scholnik A, Wulfekuhler L, Dimitrov N. Non-Small-Cell Lung Cancer Associated With Excessive Eosinophilia and Secretion of Interleukin-5 as a Paraneoplastic Syndrome. Am J Hematol (2007) 82(3):234-7. doi: 10.1002/ajh.20789

28. Sans-Sabrafen J, Buxó-Costa J, Woessner S, Florensa L, Besses C, Malats N, et al. Myelodysplastic Syndromes and Malignant Solid Tumors: Analysis of 21 Cases. Am J Hematol (1992) 41(1):1-4. doi: 10.1002/ajh.2830410102

29. Okada A, Higashihara T, Kusano T, Takemura K, Saigusa H, Maruno S, et al. IL-6-Producing Renal Cell Carcinoma Causing Renal and Endocrine Paraneoplastic Syndromes. Intern Med (2019) 58(13):1953-60. doi: 10.2169/ internalmedicine.2000-18
30. Barton BE. Interleukin-6 and New Strategies for the Treatment of Cancer, Hyperproliferative Diseases and Paraneoplastic Syndromes. Expert Opin Ther Targets (2005) 9(4):737-52. doi: 10.1517/14728222.9.4.737

31. Kancharla Pa, Surapaneni BKb, Goldfinger Ma, Hennrick Ka, Ozeri DJa. Paraneoplastic Seronegative Pauci-Immune Glomerulonephritis Associated With Lung Adenocarcinoma Responds to Rituximab: A Case Report. Case Rep Oncol (2018) 11(2):372-7. doi: 10.1159/000490101

32. Golden EB, Demaria S, Schiff PB, Chachoua A, Formenti SC. An Abscopal Response to Radiation and Ipilimumab in a Patient With Metastatic nonSmall Cell Lung Cancer. Cancer Immunol Res (2013) 1(6):365-72. doi: 10.1158/2326-6066.CIR-13-0115

33. Fu ZZ, Peng Y, Cao LY, Chen YS, Li K, Fu BH. Correlations Between Serum IL-6 Levels and Radiation Pneumonitis in Lung Cancer Patients: A MetaAnalysis. J Clin Lab Anal (2016) 30(2):145-54. doi: 10.1002/jcla.21828

Conflict of Interest: KAM is on the advisory boards of Amgen, AstraZeneca, and Mirati Therapeutics. KRV disclosures include the following: honorariumPhysicians' Education Resource, Consultant-AstraZeneca.

The remaining authors declare that the research was conducted in the absence of any commercial or financial relationships that could be construed as a potential conflict of interest.

Publisher's Note: All claims expressed in this article are solely those of the authors and do not necessarily represent those of their affiliated organizations, or those of the publisher, the editors and the reviewers. Any product that may be evaluated in this article, or claim that may be made by its manufacturer, is not guaranteed or endorsed by the publisher.

Copyright $\odot 2022$ Sloan, Naik, Umrau, Xian, Marrone and Voong. This is an openaccess article distributed under the terms of the Creative Commons Attribution License (CC BY). The use, distribution or reproduction in other forums is permitted, provided the original author(s) and the copyright owner(s) are credited and that the original publication in this journal is cited, in accordance with accepted academic practice. No use, distribution or reproduction is permitted which does not comply with these terms. 